\title{
Purification of Rickettsiales-like organisms associated with Pecten maximus (Mollusca: Bivalvia): serological and biochemical characterization
}

\author{
G. Le Gall, E. Mialhe* \\ IFREMER, Laboratoire de Biologie et d'Ecologie des Invertébrés Marins, Unité de Recherche en Pathologie, Immunologie et \\ Génétique Moléculaire, B.P. 133, F-17390 La Tremblade, France
}

\begin{abstract}
Significant mortalities have been observed in populations of Saint-Jacques scallops Pecten maximus, in association with numerous intracellular colonies of Rickettsiales-like organisms (RLO) in the gills. Isolation of the procaryotes from infected tissues and their subsequent purification were achieved by a specific protocol based on differential and isopycnic centrifugations on sucrose and renografin density gradients. The purity and integrity of purified procaryotes were verified by electron microscopy. Specific polyclonal antibodies were prepared for serological characterization. Fifteen major constituent proteins were electrophoretically identified, their molecular weights ranging between 148 and $16 \mathrm{kD}$. Ten enzyme activities were biochemically identified, including acid phosphatase and catalase, which could be related to procaryote pathogenicity.
\end{abstract}

\section{INTRODUCTION}

Intracellular procaryotes have been reported in many invertebrate groups, but only a few have been extensively investigated, namely, those that are related to human, animal or plant pathology and transmitted by hematophagous or phytophagous insects and arachnids (Weiss 1981, 1982, Weiss \& Dasch 1981). Studies on biological control of pests have also contributed to knowledge about some insect-specific procaryotes (Leu et al. 1989). The association of intracellular procaryotes with arthropod hosts appeared in some cases to be truly symbiotic. Because of the impact of infectious diseases on mollusc production in recent years, new interest has been devoted to intracellular procaryotes (Lauckner 1983). Morphologically, these procaryotes were related to the Chlamydiales (Moulder 1984) or the Rickettsiales (Weiss \& Moulder 1984). In the majority of cases associated with mass mortalities, they were identified as Rickettsiales-like organisms (RLO).

- Addressee for correspondence
Among the molluscan species concerned, some cases were described in the Pectinidae family (Gulka et al. 1983, Elston 1986). Populations of Pecten maximus suffered heavy losses during recent winters in France, and the only detected microorganism that was a potential pathogen was a gill Rickettsiales-like organism (Le Gall et al. 1988). An epizootiological survey has subsequently been used to argue the pathogenic status of this organism; however, environmental factors may also be synergistically involved (Le Gall et al. 1991b). In order to better understand the significance of mollusc RLO in terms of pathogenicity, epidemiology and taxonomy, it is first necessary to isolate and characterize them.

In this paper, an original protocol is described for purifying the RLO from infected gills of Pecten maximus. Some protocols have been established for vertebrate Rickettsiales which can be cultivated in the yolk sac of chicken embryos (Dasch \& Weiss 1977, Williams et al. 1981) or grown in tissue cultures (Weiss et al. 1975), but no prior methodology exists for purification directly from naturally infected invertebrate tissues. 
Because of the lack of molluscan cell lines for in vitro culture of specific intracellular procaryotes, the most obvious method for purifying RLO was to apply centrifugation techniques that have been successfully used to purify intracellular protozoans from infected oyster tissues (Mialhe et al. 1985, 1988).

The availability of highly purified procaryote suspensions permitted the preparation of specific polyclonal antibodies, the electrophoretic characterization of major proteins and the biochemical identification of enzymes, some possibly related to pathogenicity.

\section{MATERIALS AND METHODS}

Scallops. Infected 2 to 4 yr old Saint-Jacques scallops Pecten maximus were collected by dredging in the Saint-Brieuc Bay (Brittany, France), where Rickettsiales-like procaryote prevalences are maximal (Le Gall et al. 1991b). Healthy scallops were obtained from Norway (S. Mortensen).

Light and electron microscopy. For light microscopy, infected gill smears, homogenates or procaryote suspensions, at different steps of purification, were airdried on glass slides and then fixed and stained with a Hemacolor kit (Merck). For electron microscopy, pellets of purified RLO were fixed in sodium cacodylate/ $\mathrm{HCl}$ buffer $(0.1 \mathrm{M})$, glutaraldehyde $(1.25 \%)$ and paraformaldehyde $(2 \%)$, pH 7.4 . The osmolarity was raised to $1100 \mathrm{mOsm}$ with sucrose and measured with an automatic cryoosmometer (Knauer). The specimens were then prepared and embedded in resin (LX 112) using an LKB ultraprocessor automat. Ultrathin sections were contrasted with lead citrate and aqueous uranyl acetate by means of an LKB ultrastainer automat. Grids were examined with a Jeol 1200 CX electron microscope.

Purification protocol. The scallop gills were thoroughly and vigorously washed with filtered $(0.22$ $\mu \mathrm{m})$ seawater with Tween 80 added $(0.1 \%)$ (FSWT). The gills were then dissected and homogenized with an Ultra-Turrax homogenizer (Janke \& Kunkel GmbH) in FSWT (100 ml per scallop). The homogenates were sieved successively through 300,60 and $25 \mu \mathrm{m}$ nylon meshes to remove large fibrous fragments and resulting suspensions were centrifuged $(3500 \times 9,30 \mathrm{~min}$ $6^{\circ} \mathrm{C}$ ). The pellets were resuspended in FSWT with Ultra-Turrax and again centrifuged. The pellets were resuspended as described previously, and centrifuged through a $15 \%(w / w)$ sucrose solution in FSWT $(3200 \times$ g, $\left.30 \mathrm{~min}, 6^{\circ} \mathrm{C}\right)$. The pellets were removed and centrifuged again on $50 \%(\mathrm{w} / \mathrm{w})$ sucrose cushion in FSWT $\left(3200 \times g, 30 \mathrm{~min}, 6^{\circ} \mathrm{C}\right)$. The interface fractions were collected, diluted 5-fold very slowly in FSWT and pelleted $\left(3500 \times g, 30 \mathrm{~min}, 6^{\circ} \mathrm{C}\right)$.
The resulting pellets were resuspended in HN buffer [HEPES (N-2-hydroxyethy] piperazine $\mathrm{N}$-2-ethane sulfonic acid) $20 \mathrm{mM}, \mathrm{NaCl} 0.5 \mathrm{M}, \mathrm{pH} 7.5,1000 \mathrm{mOsm}]$ and layered on $25 \mathrm{ml}$ Renografin discontinuous gradient $(14 \%$ to $21 \%$ to $28 \%)(v / v)$ prepared from the commercial product Radioselectan $76 \%$ (Schering Laboratories). For this purpose, 1 vol of Radioselectan $76 \%$ (osmotic pressure $1800 \mathrm{mOsm}$ ) was diluted with $0.8 \mathrm{vol}$ of distilled water to obtain a Renografin $42 \%$ solution which was iso-osmotic with scallop hemolymph. The different concentrations were then easily prepared by diluting the Renografin $42 \%$ with suitable volumes of $\mathrm{HN}$ buffer. After isopycnic centrifugation in a $50.2 \mathrm{Ti}$ Beckman rotor $\left(300000 \times \mathrm{g}, 30 \mathrm{~min}, 6^{\circ} \mathrm{C}\right)$, the major band at the $21 \%-28 \%$ interface was collected with a long needle and the fractions from all of the tubes were regrouped, diluted 5-fold with $\mathrm{HN}$ buffer to reduce the density of the Renografin solution and centrifuged $\left(50000 \times g, 30 \mathrm{~min}, 6^{\circ} \mathrm{C}\right)$ in order to pellet the purified procaryotes. The number of procaryotes was routinely determined by observation using a Malassez cell at $400 \times$ magnification.

Specific polyclonal antibody preparation. Mice were immunized over a $4 \mathrm{wk}$ period by intravenous and intraperitoneal injections of purified procaryote suspensions made at weekly intervals. Immunosera were collected $15 \mathrm{~d}$ after the third booster injection and clarified by centrifugation.

Indirect immunoiluorescence (IIF). Gill smears of healthy and diseased scallops were air-dried and fixed in acetone $(10 \mathrm{~min})$. They were then overlaid with the immunoserum diluted from $1 / 10$ to $1 / 5000$ in IIF buffer (Institut Pasteur Diagnostic). After a 20 min incubation period at room temperature in a moist chamber, the slides were washed with IIF buffer and then overlaid with fluorescein isothiocyanate (FITC)-conjugated goat anti-mouse immunoglobulin antiserum (Institut Pasteur Diagnostic) diluted (1/100) in IIF buffer with Evans Blue $(0.01 \%)$. The slides were again incubated in a moist chamber for $20 \mathrm{~min}$ and washed in IIF buffer. The slides were examined for bright green fluorescent RLO cells. The control antibodies consisted of sera from nonimmunized mice.

SDS-polyacrylamide gel electrophoresis (SDSPAGE). SDS-PAGE was performed using the PhastSystem (Pharmacia LKB). Purified procaryote suspensions $\left(10^{8}\right.$ procaryotes $\left.\mathrm{ml}^{-1}\right)$ were frozen, thawed and boiled ( $5 \mathrm{~min}$ ) in sample buffer ( $4 \%$ sodium-dodecylsulfate (SDS); $5 \% \beta$-mercaptoethanol). The procaryote samples and the molecular-weight markers (Pharmacia) were deposited ( $1 \mu \mathrm{l}$ ) on a polyacrylamide gradient gel ready to use $(10 \%-15 \%)$ and current was then applied $\left(10 \mathrm{~mA}, 15^{\circ} \mathrm{C}\right)$. The gels were treated according to the protocol of Pharmacia LKB for silver staining.

Enzymatic activity characterization. Using the API 
ZYM system (API SYSTEM, La Balme les Grottes, France), 19 enzymatic activities were examined from purified procaryote suspensions $\left(10^{8}\right.$ procaryotes $\left.\mathrm{ml}^{-1}\right)$ previously frozen, thawed and homogenized by ultrasound (100 W, 60 s). The wells of the API ZYM plate were filled with $65 \mu \mathrm{l}$ of different dilutions of the procaryote stock homogenate. After incubation $\left(37^{\circ} \mathrm{C}\right.$, $4 \mathrm{~h}$ ), the plates were treated according to the standard protocol of the supplier (API SYSTEM).

Acid phosphatase was also estimated by colorimetry using the degradation of phenylphosphate to phenol and phosphate at pH 4.9 (Kit Biomerieux). The reactions were performed with $100 \mu \mathrm{l}$ of procaryote homogenate, equivalent to $10^{7}$ cells. Moreover, the Ltartrate resistant acid phosphatases were estimated in parallel. The activities were expressed in nmol min ${ }^{-1}$ per $10^{6}$ procaryotes by reference to a control equivalent to $20 \mathrm{Kind}$ and King units ( 1 unit is equivalent to the enzyme quantity producing $1 \mathrm{mg} \mathrm{h}^{-1}$ at $37^{\circ} \mathrm{C}$ ).

Catalase was demonstrated by the production of oxygen resulting from the degradation of hydrogen peroxide. A drop of purified procaryotes (about $5 \times 10^{4}$ ) was mixed with hydrogen peroxide $(3 \%)$ and the production of bubbles was observed under binocular magnification.

\section{RESULTS}

\section{Purification protocol}

Histological study of this Rickettsiales-like organism has shown that the infection is limited to the gills (Le Gall et al, 1988). Thus, the purification protocol (Fig. 1) was performed only with gill tissues that had been thoroughly and vigorously washed with filtered seawater and $0.1 \%$ Tween 80 detergent to eliminate microorganisms and inert material that contaminate the external surfaces of gills. Tween 80 detergent was selected because it had previously proved very efficient for limiting aggregation without any deleterious effect on protozoans like Bonamia ostreae (Mialhe et al. 1988). The gills were dissected and homogenized in FSWT with an Ultra Turrax tissue homogenizer, which is well suited for dissociation of scallop cells without damage to the RLO. Relatively large volumes of FSWT were used for the initial homogenization step $(100 \mathrm{ml}$ for the gills of one scallop) in order to obtain very fluid homogenates. The subsequent straining of the homogenates through different nylon meshes was a simple and efficient way to remove large amounts of fibrous materials. The resulting homogenates, as shown by light microscopic examination, contained many intact nuclei, amorphous material and numerous RLO. The first centrifugation eliminated soluble material and concentrated RLO. The second centrifugation produced pellets containing essentially particu- late matter. Centrifugation of the resuspended pellets through a $15 \%$ sucrose solution eliminated thinner fragments. At the $50 \%$ sucrose stage the pellet contained primarily nuclei and the supernatant appeared opalescent. The RLO were located at the interface with nuclei. These fractions were collected and diluted with FSWT very slowly to avoid submitting the procaryotes to osmotic shock, and then centrifuged to pellet them.

During isopycnic centrifugation, the RLO formed a minor band at the 14\%-21\% interface containing primarily nuclei and formed a major band at the $21 \%-28 \%$ interface with only a few nuclei present. This last band was collected.

During the different steps of this purification pro-

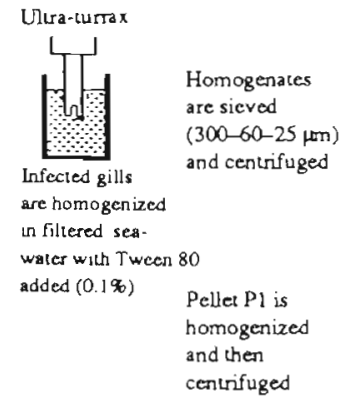

Pellet $\mathrm{P2}$ is homogenized and centrifuged through a $15 \%$ sucrose cushion

Pellet P3 is resuspended and centrifuged on a $50 \%$ sucrose cushion

Interface is diluted in $\mathrm{HN}$ buffer (HEPES $20 \mathrm{mM}$; $\mathrm{NaCl} 0.5 \mathrm{M}$; $\mathrm{pH} 7.5$ ) and then pelleted

Pellet P4 is resuspended in HN buffer and then centrifuged through a density gradient of Renografin (14\%-21\%-28\%)

Interface with $\operatorname{RLO}(21 \%-28 \%)$ is collested. diluted in HNB and purified
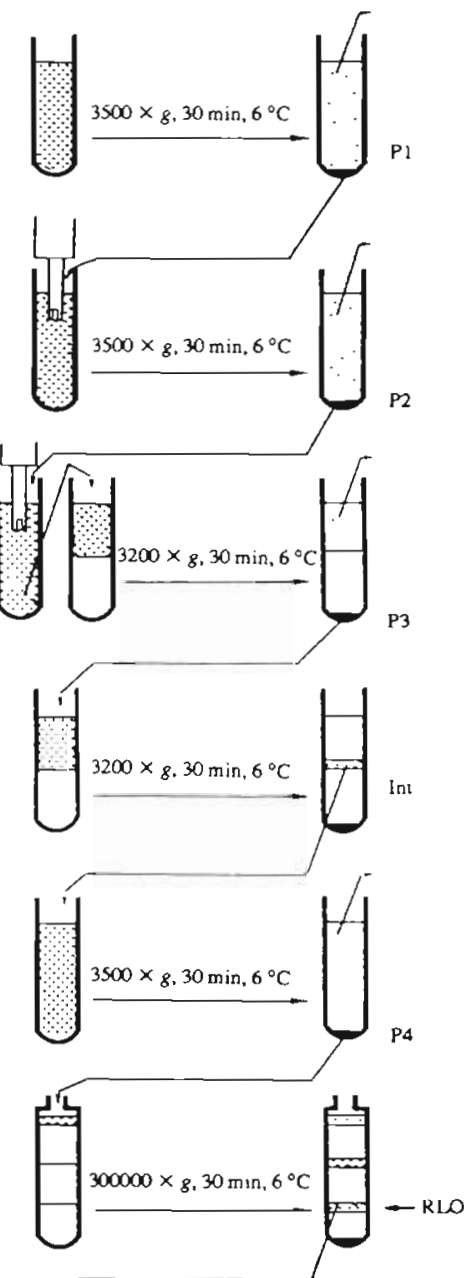
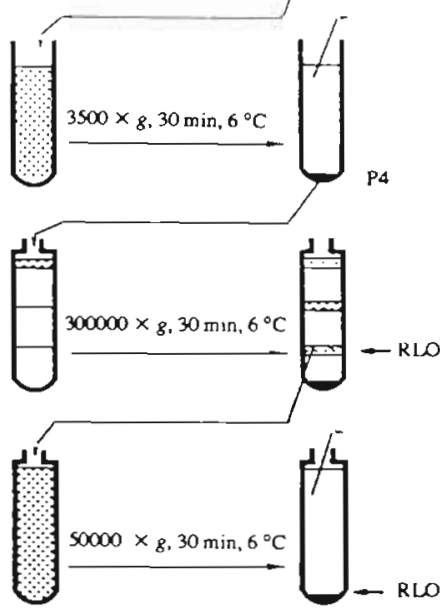

Fig. 1. Protocol for purification of Rickettsiales-like organisms (RLO) from infected gills of St-Jacques scallop Pecten maximus 
tocol, the RLO were located in the different fractions by light microscopic examination of stained preparations, since this Rickettsiales-like procaryote can be easily recognized by its size and globular morphology. In these studies, the number of purified procaryotes per scallop varied, but was as high as $10^{8}$

\section{Examination of purified products}

Electron microscopy. Ultrastructural examination of the purified microorganisms allowed identification of characteristics, particularly the wall structure, which demonstrated that they were the gill Rickettsiales-like procaryotes of Pecten maximus (Le Gall et al. 1988). Moreover, the micrographs revealed the morphological integrity of purified procaryotes and the homogeneity of procaryote suspensions (Fig. 2)

Indirect immunofluorescence. The sera of immunized and control mice were tested against gill smears of healthy Norwegian and diseased French scallops. Specific recognition of procaryote cells without background noise was obtained for the dilution range between $1 / 100$ and 1/1000. The optimal concentration was 1/500. No fluorescence was observed from healthy Norwegian scallops or with control sera.

\section{Biochemical characterization of purified procaryotes}

Electrophoretic pattern of proteins. Fifteen major proteins (P1 to P15) were identified by SDS-PAGE, the initial sample deposit being equivalent to about $10^{5}$ procaryotes. Their molecular weights, estimated by
Table 1. Enzymatic activity characterization, for suspensions of Rickettsiales-like organisms purified from Pecten maximus, using the API ZYM system; index values are indicated

\begin{tabular}{|llc|}
\hline Enzymes & Abbreviation & Index \\
\hline Alkaline phosphatase & ALP & + \\
Esterase (C4) & EST(C4) & ++ \\
Esterase lipase (C8) & ELIP & + \\
Lipase (C14) & LIP & 0 \\
Leucine arylamidase & LAA & + \\
Valine arylamidase & VAA & 0 \\
Cystine arylamidase & CAA & 0 \\
Trypsine & TR & 0 \\
$\alpha$-Chemotrypsin & CTR & 0 \\
Acid phosphatase & ACP & + \\
Phosphoaminidase & PH & ++ \\
$\alpha$-Galactosidase & $\alpha$ GAL & 0 \\
$\beta$-Galactosidase & $\beta$ GAL & + \\
$\beta$-Glucuronidase & $\beta G L U$ & 0 \\
$\alpha$-Glucosidase & $\alpha$ GLC & 0 \\
$\beta$-Glucosidase & $\beta G L C$ & 0 \\
$N$-acetyl- $\beta$-glucosaminidase & AGLA & + \\
$\alpha$-Mannosidase & $\alpha M A N$ & 0 \\
$\alpha$-Fucosidase & $\alpha$ FUC & + \\
\hline
\end{tabular}

comparison with the electrophoretic mobilities of reference proteins, ranged between 148 and $16 \mathrm{kD}$ : P1, 148 kD; P2, $143 \mathrm{kD} ; \mathrm{P} 3,100 \mathrm{kD} ;$ P4, $88 \mathrm{kD}$; P5, $74 \mathrm{kD}$; P6, 70 kD; P7, 52 kD; P8, 48 kD; P9, 39.5 kD; P10 34.5 kD; P11, $31 \mathrm{kD}$; P12, $24 \mathrm{kD} ; \mathrm{P} 13,22.5 \mathrm{kD} ; \mathrm{P} 14,20 \mathrm{kD} ; \mathrm{P} 15,16 \mathrm{kD}$.

Enzymatic activities. Only 9 enzymatic activities were detected from ca $6.5 \times 10^{6}$ isolated procaryotes. They were alkaline phosphatase, esterase (C4), esterase lipase $(\mathrm{C} 8)$, leucine arylamidase, acid phosphatase, phosphoaminidase, $\beta$-galactosidase, $N$-acetyl- $\beta$-glucosaminidase and $\alpha$-fucosidase (Table 1). Among these

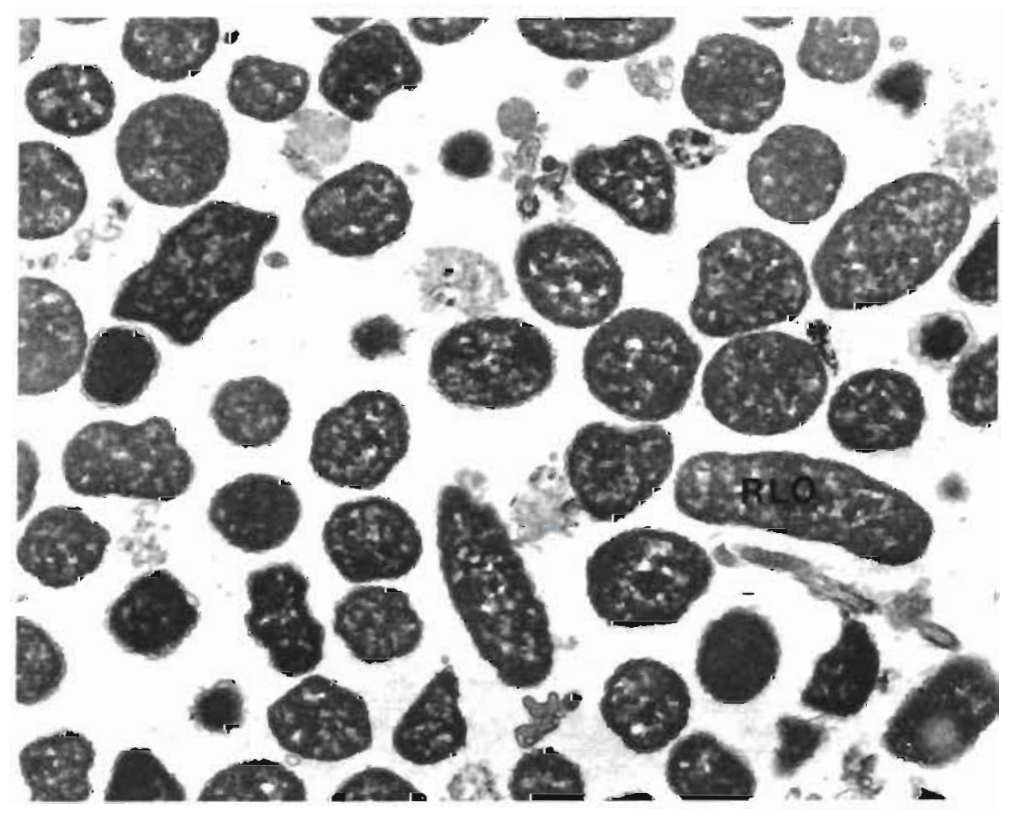

Fig. 2. Ultrastructure of purified Rickettsiales-like organisms (RLO) from Pecten maximus. Electron microscopy, $\times 10000$ 
enzymes, esterase and phosphoaminidase had the greatest activity.

The presence of acid phosphatase was confirmed using another commercially available microassay (Biomérieux), which allows better quantification of the enzymatic activities and an estimation of their sensitivity to L-tartrate. On the basis of 4 different analyses, the acid phosphatase activity was estimated at $17.7( \pm 8.8)$ nmol $\mathrm{min}^{-1}$ per $10^{6}$ procaryotes. Inhibition by L-tartrate was estimated at $26 \%$ since the values were decreased to $13.2( \pm 10.4) \mathrm{nmol} \mathrm{min}^{-1}$ per $10^{6}$ procaryotes in the presence of this chemical. Additionally, catalase was detected on the basis of a quick degradation of hydrogen peroxide by procaryotes.

\section{DISCUSSION}

Electron microscope examination and specific immunofluorescence techniques demonstrated that the products of the purification protocol were the same procaryotes as the gill RLO associated with Pecten maximus. This is an original protocol in the field of mollusc pathology, for which several Rickettsiales-like procaryotes have been reported. It is unique because it demonstrates the purification of intracellular procaryotes directly from infected marine invertebrate tissue without previous in vitro culture, either into the yolk sac of chicken embryo or on cell lines as is usually necessary with vertebrate and insect rickettsias (Welburn et al. 1987). This may be advantageous for isolating RLO from different invertebrate groups for which the lack of cell lines continues to be a barrier to the study of intracellular pathogens. Two other Rickettsiales-like organisms found in 2 pectinids, Chlamys opercularis and Patinopecten yessoensis, have been purified in this manner (authors' unpubl.)

In view of the complex initial tissue homogenates, this protocol was very effective. This was confirmed by the specificity of immunosera, which did not need to be purified with acetone powder from healthy scallop tissues for eliminating antibodies directed to contaminant or scallop antigens.

The ability to obtain relatively large quantities of purified suspensions permitted biochemical characterization of the RLO. First, a protein pattern was established leading to identification of 15 major proteins whose molecular weights range between 148 and 16 $\mathrm{kD}$. One of them, P9 $(39.5 \mathrm{kD})$, may be related to the matrix protein from the outer membrane of gram negative bacteria (Lugtenberg et al. 1977). The use of the miniaturized system was very suitable for simple protein pattern recognition, as results were obtained with only $1 \mu$ from a suspension of $10^{8}$ procaryotes $\mathrm{ml}^{-1}$. The use of Renografin was well suited for the study of rickettsial enzymatic activity here and in a previous study (Weiss et al. 1975) and appeared to have no effect on parasite metabolic and antigenic properties.

The use of the miniaturized API ZYM system was previously applied to biochemical identification of bacteria (Humble et al. 1977, Tharagonnet et al. 1977), Trypanosoma sp. protozoans (Kirkpatrick et al. 1985) or Penicillium fungi (Bridge \& Hawksworth 1984). In this study several enzymatic activities were identified, 2 of which may be related to intracellular procaryote pathogenicity. The first one is catalase, which is involved in detoxification of hydrogen peroxide produced during phagocytosis (Roos 1980). This enzyme was previously demonstrated in Coxiella burnetii, an intravacuolar Rickettsiales of vertebrates (Akporiaye \& Baca 1983). The second one is acid phosphatase, whose activity was quantified and sensitivity to L-tartrate was demonstrated. Several acid phosphatases have been characterized in intracellular protozoans belonging to Leishmania species (Gottlieb \& Dwyer 1981), one of them being L-tartrate resistant. Its ability to reduce phagocytic cell production of toxic oxygen metabolites suggests that this enzyme may be important for intracellular survival of the parasite (Remaley et al. 1984). This hypothesis was recently confirmed for the Pecten maximus RLO in experiments to study the in vitro interactions between hemocytes and purified procaryotes (Le Gall et al. 1991a). These investigations of mollusc response to RLO illustrate one application of the purification protocol for studying the microbiocidal mechanisms of hemocytes and pathogen adaptations for intracellular survival (Moulder 1985).

The Rickettsiales-like procaryotes of Pecten maximus have been characterized biochemically and serologically and it may be assumed that these methodologies can be extrapolated to the microorganisms associated with other molluscan species. It would then become possible to better define the host range and the taxonomic positions of the molluscan Rickettsialeslike organisms within this class of procaryotes (Williams et al. 1981, Weiss 1982, Urakami et al. 1986, Weiss et al. 1987, Leu et al. 1989).

Finally, the ability to purify Rickettsiales-like procaryotes from molluscs makes possible experimental investigation of the mechanism of infection in terms of vertical and/or horizontal transmission.

Acknowledgement. We are grateful to D. Chagot for her technical assistance in electron microscopy.

\section{LITERATURE CITED}

Akporiaye, E. T., Baca, O. G. (1983). Superoxide anion production and superoxide dismutase and catalase activities in Coxiella burnetii. J. Bact. 154: 520-523 
Bridge, P. D. Hawksworth, D. L. (1984). The API ZYM enzyme testing system as an aid to the rapid identification of Penicillium isolates. Microbiol. Sci. 1: 232-234

Dasch, G. A., Weiss, E. (1977). Characterization of the Madrid E strain of Rickettsia prowazekii purified by Renografin density gradient centrifugation. Infection Immunity 15 280-286

Elston, R. A. (1986). Occurrence of branchial Rickettsiales-like infections in two bivalve molluscs, Tapes japonica and patinopecten yessoensis, with comments on their significance. J. Fish. Dis. 9: 69-71

Gottlieb, M., Dwyer, D. W. (1981). Leishmania donovani: surface membrane acid phosphatase activity of promastigotes. Exp. Parasitol. 52: 117-128

Gulka, G., Chang, P. W., Marti, K. A. (1983). Prokaryotic infection associated with a mass mortality of the sea scallop Placopecten magellanicus. J. Fish Dis., 6: 355-364

Humble, M. W., King, A., Phillips, I. (1977). API ZYM: a simple rapid system for the detection of bacienidi enzymes. J. clini. Pathol. 30: 275-277

Kirkpatrick, C. E., Terway-Thompson, C. A., Raja Iyengar, M (1985). Biochemical characterization of some raptor trypanosomes. II. Enzyme studies, with a description of $T_{r y}$ panosoma bennetti n. sp. Can. J. Zool. 64: 195-203

Lauckner, G. (1983). Diseases of Mollusca: Bivalvia. In: Kinne, O. (ed.) Diseases of marine animals, Vol. II. Biologische Anstalt Helgoland, Hamburg, p. 477-961

Le Gall, G., Bachère, E., Mialhe, E. (1991a). Chemiluminescence analysis of the activity of Pecten maximus hemocytes stimulated with zymosan and host-specific Rickettsiales-like organisms. Dis. aquat. Org. 11 181-186

Le Gall, G., Chagot, D., Mialhe, E., Grizel, H. (1988). Branchial rickettsiales-like infection associated with a mass mortality of sea scallop Pecten maximus. Dis. aquat. Org. 4: 229-232

Le Gall, G., Mialhe, E., Chagot, D., Grizel, H. (1991b). Epizootiological study of rickettsiosis of the Saint-Jacques scallop Pecten maximus. Dis. aquat. Org. 10: 139-145

Leu, S. J. C., Li, J. K. K., Hsiao, T. H. (1989). Characterization of Wolbachia postica, the cause of reproductive incompatibility among Alfalfa weevil strains. J. Invertebr. Pathol. 54: 248-259

Lugtenberg, B., Bronstein, H., Selm, N. V., Peters, R. (1977). Peptidoglycan-associated outer membrane proteins in gram negative bacteria. Biochim. biophys. Acta 465: 571-578

Mialhe, E., Bachère, E., Chagot, D., Grizel, H. (1988). Isolation and purification of Protozoa Bonamia ostreae (Pichot et al. 1980), a parasite affecting the flat oyster Ostrea edulis L. Aquaculture 71: 293-299.

Mialhe, E., Bachère, E., Le Bec, C., Grizel, H. (1985). Isolement et purification de Marteilia (Protozoa: Ascetospora) parasite de bivalves marins. C. R. Acad. Sci. Paris 301 1 137-142

Responsible Subject Editor A. K. Sparks, Seattle, Washington, USA
Moulder, J. W (1984). The rickettsias and chlamydias. Order II. Chlamydiales. In: Krieg, N. R., Holt, J. G. (eds.) Bergey's manual of systematic bacteriology, Vol. 1. Williams \& Wilkins, Baitimore, p. 729-739

Moulder, J. W. (1985). Comparative biology of intracellular parasitism. Microbiol. Rev. 49: 298-337

Remaley, A. T., Kuhns, D. B., Basford, R. E., Glew, R. H., Kaplan, S. S. (1984). Leishmanial phosphatase blocks neutrophil $\mathrm{O}_{2}$-production. J. biol. Chem. 259: 11173-11175

Roos, D. (1980). The metabolic response to phagocytosis. In: Weissman, G. (ed.) The cell biology of inflammation. Elsevier, Amsterdam, p. 337-385

Tharagonnet, D., Sisson, P. R., Rosby, C. M., Ingham, H. R., Selkon, J. B. (1977). The API ZYM system in the identification of gram negative anerobes. J. clin. Pathol. 30: 505-509

Urakami, H., Ohashi, N., Tsuruhara, T., Tamura, A. (1986). Characterization of polypeptides in Rickettsia tsutsugamushi: effect of preparative conditions on migration of polypeptides in polyacrylamide gel electrophoresis. Infection Immunity 51: 948-952

Weiss, E. (1981). The family Rickettsiaceae: human pathogens. In: Starr, M. P., Stolp, H., Trüper, H. G., Balows, A., Schlegel, H. G. (eds.) The procaryotes: a handbook on habitats, isolation and identification of bacteria, Vol. 2 . Springer-Verlag, Berlin, p. 2137-2160

Weiss, E. (1982). The biology of Rickettsiae. Ann. Rev. Microbiol. 36: 345-370

Weiss, E., Coolbaugh, J. C., Williams, J. C. (1975). Separation of viable Rickettsia typhi from yolk sac and L cell host components by Renografin density gradient centrifugation. Appl. Microbiol. 30: 456-463

Weiss, E., Dasch, G. A. (1981). The family Rickettsiaceae: pathogens of domestic animals and invertebrates; nonpathogenic arthropod symbiotes. In: Starr, M. P., Stolp, H., Trüper, H. G., Balows, A., Schlegel, H. G. (eds.) The procaryotes: a handbook on habitats, isolation and identification of bacteria, Vol. 2. Springer-Verlag, Berlin, p. $2161-2171$

Weiss, E., Dobson, M. E., Dasch, G. A. (1987). Biochemistry of Rickettsiae: recent advances. Acta Virol., 31: 271-286

Weiss, E., Moulder, J. W. (1984). The rickettsias and chlamydias. Order I. Rickettsiales. In: Krieg, N. R., Holt, J. G. (eds.) Bergey's manual of systematic bacteriology, Vol. 1 Williams \& Wilkins, Baltimore, p. 687-729

Welburn, S. C., Mandlin, I., Ellis, D. S. (1987). In vitro cultivation of Rickettsia-like organisms from Glossina sp. Ann. trop. Med. Parasitol. 81: 331-335

Williams, J. C., Peacock, M. G., McCaul, T F. (1981) Immunological and biological characterization of Coxiella burnetii, phases I and II, separated from host components Infection Immunity 32: 840-851

Manuscript first received: June 14, 1991

Revised version accepted: December 12, 1991 